\title{
The expatriate information flow model: Towards understanding Internet usage in the Kingdom of Saudi Arabia
}

\author{
Marie Hattingh*, Machdel Matthee*, Hugo Lotriet ${ }^{\dagger}$ \\ * Department of Informatics, University of Pretoria, South Africa \\ †School of Computing, University of South Africa, South Africa
}

\begin{abstract}
Expatriate adjustment research has identified a number of challenges that expatriates experience when adjusting to the host country. These include spousal influence, cultural training/understanding, fluency in the host language and the personality or emotional readiness of the expatriate. These challenges are amplified when considered in the Kingdom of Saudi Arabia (KSA), which has large cultural distance when compared to the average Western culture and therefore provides a setting for an interesting study. This paper describes how the "degree of information flow", a substantive category derived through the grounded theory methodology, provides an understanding of the emotional relationship expatriates in KSA have with the Internet. An expatriate information flow model was developed explaining the pre-conditions to and the consequences of information flow. The paper shows that the pre-conditions to information flow include overcoming the challenges experienced by Internet users in KSA in addition to their intention to use the Internet based on their personal needs, status and personality. The consequences of information flow were indicated as having an overall positive impact on the expatriate's well-being. This was operationalised as giving expatriates an extended control over their environment, increased social presence and an increased exchange of information between the expatriates and their benevolent communities.
\end{abstract}

KEYWORDS: expatriate, Internet, culture, degree of isolation, degree of information flow, Kingdom of Saudi Arabia, well-being

CATEGORIES: K.4.0

\section{INTRODUCTION}

Expatriate research has extensively shown that expatriates experience a number of challenges when adapting to their new environment. Examples of these challenges include spousal adjustment to the new environment and support [1], lack of cross cultural training/understanding [1] [2], fluency in the host language [2], and expatriate personality or emotional immaturity [3]. These factors are important due to the rise in deployment and use of expatriates by organizations [4], high costs associated with deployment [1], and the emotional upheaval for expatriate families [2]. Due to its ubiquity in everyday life, the potential exists for the Internet to aid expatriates in overcoming these challenges. Studies that have investigated the use of the Internet by expatriates include the use of websites to assist expatriate families in political crises through the provision of inexpensive information [5], and as a resource for migrants to increase social capital [6].

According to a 2007 survey, a third of the population in Kingdom of Saudi Arabia (KSA) is expatriates [7]. Islamic (Shari'a) law, which is derived from the

\footnotetext{
Email: Marie Hattingh mariehattingh@yahoo.com Machdel Matthee machdel.matthee@up.ac.za, Hugo Lotriet lotrihh@unisa.ac.za
}

Qur'an, is enforced and as a result very strict rules with regards to dress, the use of alcohol and moral behavior apply to all residents. In KSA women are not freely allowed to work, drive or even vote. The majority of expatriates are male and when referring to a spouse, this study is referring to the wife of a male expatriate. During their stay, expatriates have to abide by the laws and moral standards of the government and people of the host country. Breaches of these rules may not be crimes in Western society but will be treated as punishable crimes in KSA [7]. Expatriates in this study are protected from the harsh reality of life in KSA by residing in Westernised compounds [8], which afford them more freedom. In a previous paper [9], the lead researcher and first author discussed the large cultural distance between KSA culture and the culture of the home countries of the expatriates.

Against this background, this paper reports on an on-going research project that aims to contribute towards a better understanding of the role of the Internet in expatriate adjustment in the KSA. Previous papers on this study are referenced in [9] and [10] The study was conducted in Riyadh, the capital of KSA. The aim of this study is to develop a substantive grounded theory (a theory that relates to a specific area of enquiry) that will provide an understanding of the patterns of expatriate behaviour related to Internet 
usage in KSA. The study has established that the core concern, which is the main social problem that expatriates in this study experience, can be conceptualised as "negotiating adjustment in KSA". This describes how expatriates adjust to life in KSA where a number of emotional and physical challenges must be overcome before they can reach a steady state of contentment. "Internet a lifeline to the real world" has emerged as the core category and "degree of isolation" and "degree of information flow" as substantive categories. A core category is a category that recurs constantly in the data and integrates all other categories, thereby providing an explanatory whole to the data [11]. The study has already proposed a theoretical model which presents a high level of abstraction of a set of interrelated categories as presented in Figure 1. It will constitute the substantive theory of the lived experiences of KSA expatriates regarding the role of the Internet in negotiating adjustment to life in KSA. Figure 1 depicts the relationships between the core category and the other substantive categories.

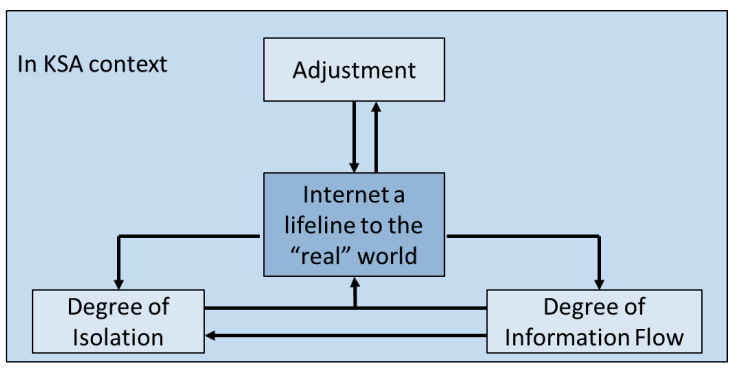

Figure 1: Proposed model of negotiating adjustment in KSA by using Internet as a lifeline to the real world [9]

The role of the Internet to navigate the "degree of isolation" experienced by expatriates in KSA, was discussed in [9]. It was argued that the "degree of isolation" is underpinned by culture [9] and for the purposes of completeness; "culture" and "degree of isolation" will be introduced as contextual concepts that underpin the discussion of "information flow". Therefore, this paper reports on only one aspect of the theoretical model, namely the "degree of information flow" as a substantive category of expatriate adjustment in KSA. The expatriates' use of the Internet is not expected to differ significantly from the way that an average person uses the Internet anywhere else in the world. However, the outcome of using the Internet extends beyond the practical implications such as cheap instantaneous communication, the ability to read online news or do Internet banking. According to empirical data gathered as part of this study, the Internet has an impact on the emotional well-being of the expatriate; it decreases the feeling of isolation, it decreases the feeling of homesickness and creates an increased exchange of information between expatriates and the different communities in which they are involved. However, as the paper will indicate, there are a number of challenges that expatriates need to overcome to obtain the positive effects of increased information flow. The positive impact on the expatriate's emotional well-being prompts individuals to engage with their environments and participate in activities, many of which can be customised for the individual [12]. This justifies the aim of this study: to understand how expatriates use the Internet to facilitate adjustment to their current environment.

This paper begins with a brief overview of the research methodology in Section 2. Sections 3 and 4 contain brief discussions on KSA as the research setting and the contextual concept of culture. This underpins the definition of the "degree of isolation" as defined in this study, which will be briefly introduced in Section 5. The understanding of "isolation" highlights that life in KSA is not always considered "real". Therefore, the definition of "real world" versus "everyday life" will be discussed in Section 6. These contextual discussions will serve as a background to the discussions in Section 7, showing how expatriates use/experience the Internet. This will serve as an introduction against which the concept of "information flow", the focus of this paper, was defined when developing the expatriate information flow model as discussed in Section 8.

\section{RESEARCH METHODOLOGY}

The classic grounded theory method (GTM) was selected for this study. As GTM is an established method in IS research, this section is not intended to provide a complete overview of GTM. GTM is mainly an inductive exploratory process during which the lead researcher developed a substantive theory that could identify and explain structures underlying social occurrences [11]. As reported in Hattingh, Matthee and Lotriet [9] [10], the manner in which expatriates use the Internet to address their main concern, namely negotiating adjustment in KSA, is an example of a social occurrence. As soon as a substantive area was identified within the research situation [11] [13], data collection began. This allowed the lead researcher to understand what the main concern of the expatriates is. Theoretical sampling guided the lead researcher as to what questions should be posed to whom next. Theoretical sampling is where the sample groups are tailored to fit the data needed to ensure the greatest relevance to the emerging theory [11] [13].

Figure 1 denotes the matured emerging theory that conceptualises the main concerns of the expatriates in KSA that took part in this study. The development of this model followed the principles of GTM as reported in Hattingh et al. [9] [10]. This involved entering the research situation with an initial set of semi-structured and open-ended questions for the first five interviews, chosen by means of selective sampling, in order to establish a baseline framework for the theoretical sampling that followed. The interview questions were continually updated following the process of theoretical sampling. A number of categories and their properties were identified which led to the building of a significant volume of theoretical memos. Through further analysis, these categories were collapsed. This 
led to the building of a model that illustrates the relationship between categories. Following the development of a mature model, the lead researcher consulted existing literature to further inform theory development and also to determine the contribution that the theory makes to the fields of expatriate research and research related to the Internet in society. At the time of writing, twenty-two interviews have been conducted with expatriates from different nationalities, between the ages of 20 and 60 . The interviewees consisted of unaccompanied/single, accompanied, working spouses, and the nonworking spouses of expatriates. These expatriates have all been residing in KSA for between 3 months and 25 years. One interview was conducted with an employee at an Internet Service Provider on a compound. It is acknowledged by the lead researcher that, as extant literature is consulted, more interviews might be conducted to aid the further development of the proposed theoretical model.

This paper reports on the explored links between the substantive category, "degree of information flow" and extant literature. References to the other substantive category, "degree of isolation", will also be made in order to illustrate the relationship it has with expatriates as members of various communities [9]. This paper will not discuss the link between the "degree of information flow" and the core category "Internet a lifeline to the real world", as this will be discussed in detail in a future paper.

\section{RESEARCH SETTING: KINGDOM OF SAUDI ARABIA (KSA)}

KSA is an entirely Islamic (Muslim) Kingdom and Islam is embedded in nearly every aspect of life. Islam is the only religion that is allowed to be publicly practised in KSA. It is also a felony to attempt to convert Muslims to any other religion. Non-Muslims are however free to practise their own religion in the privacy of their own homes. The public display of Non-Islamic articles is not permitted and they will be confiscated on detection. Shari'a law, derived from the Qur'an is practised in KSA. The punishments prescribed by Shari'a law could be considered ruthless compared to normal Western standards. KSA, however, has a very low crime rate. Muslims throughout the world face Mecca five times a day in prayer and during these times in KSA all businesses close. Christmas and Easter, and any other Non-Muslim religious holidays are not recognised in Saudi Arabia [14].

Work and social life are divided strictly by gender. Opportunities for women (of all nationalities) to work are rare but are on the increase and women make up the staff in certain bank branches set up for women only. It is becoming more acceptable, although rare, for businesswomen to visit the KSA. However, it is still illegal for women to drive [14]. Working conditions vary depending upon the expatriate's employment contract and the company the expatriate works for. Similarly, it will depend on his job and whether the expatriate holds suitable academic or professional qualifications, whether the expatriate's family can accompany him. The expatriate's employer is also his sponsor. The sponsor is responsible for obtaining a work and residence permits and is legally responsible for the expatriate. During the expatriate's stay in KSA his sponsor will retain his passport. In return he would provide the expatriate with an identity document called an "Iqama" which should be carried at all times. Only the sponsor can obtain the necessary exit and re-entry visa, which will be put in an expatriate's passport and returned to him before he leaves. Only close family visits are allowed and only the sponsor can apply for these visit visas [14].

Women, including expatriate women, are not allowed to be accompanied by a male that is not immediate family. Accompanying a woman, for example by driving her, can lead to serious trouble with the authorities, even if you are an expatriate. Men and women that are not immediately related are not allowed to publicly socialise, for example enjoy a cup of coffee in public.

Expatriate men are expected to wear conservative clothes. Men should not appear in public in shorts above the knee or in shirts without sleeves. Additionally, it is suggested that men either refrain from wearing, or cover up, gold chains and other jewellery in public. Women, including expatriate women, have to wear an abaya, which can be described as a loose, ankle-length, cotton dress with sleeves and a high neckband. Tight fitting clothes such as pants or leggings are not recommended. All Saudi women and the majority of Muslim women cover their hair [14]. Some expatriate women cover their hair in order not to draw attention to themselves and to avoid being confronted by the Mutawwa (the Religious Police) who are often in evidence patrolling the shopping centres and who frequently challenge women on this point. However, this is a personal decision.

Western expatriates usually live in compounds where villas and apartments are available. Glasze [8] explained that the compounds of Western expatriates in Saudi Arabia were established in order to enable people with profoundly differing cultural backgrounds to live side by side. A residential compound caters for basic accommodation needs including water, power, telephone connections and furniture. Compounds provide an opportunity for newcomers to meet other expatriates, introducing them to the expatriate life style, and can include coffee mornings, toddlers' groups and shopping opportunities [14].

Expatriates do not often have an opportunity to socialise with the local community and therefore tend to form close relationships with other expatriates of "similar social status, common regional background, language, religion or profession" (MoEA, 2001, cited in [15]). A number of expatriate clubs are active throughout Riyadh [14] which affords expatriates an opportunity to connect socially. Expatriates therefore have to rely on themselves to successfully overcome the challenge of social isolation (MoEA, 2001, cited in [15]). 


\section{CONTEXTUAL CONCEPT: CULTURE}

Emerging from this study thus far is the contextual concept of culture that influences the adjustment of expatriates in general and furthermore influences the degree to which they feel isolated within KSA during their expatriate episode. Ing [16] described culture as something within and around us that is affected by and influences us. She further explains that humans strongly adhere to their culture's beliefs, look to its values in times of need, and oppose those who do not adhere to their cultural ideals. Culture is a key concept when aiming to comprehend cross-cultural adjustment. An expatriate's culture is both central to and inseparable from the individual. It is what is "mentally programmed" [17] or what provides "orientation" (Terpstra and David, 1985 cited in [18]), and it is precisely these core values which are challenged on arrival in the host country when the expatriate is confronted by a new set of "traditional ideas... (with) attached values" (Kroeber and Kluckhohn, 1952 cited in $[19$, p. 148]). This is evident in the number of models and theories available that try to make sense of cross-cultural adjustment, for example: the Integrated UCurve Theory of Cross-Cultural adjustment [20], the framework of International Adjustment by Black, Mendenhall and Oddou [21] and the model of Intercultural Adjustment by Parker and McEvoy [22].

The inherent aim of these cross-cultural adjustment theories is to understand cultural distance (CD). CD measures the extent to which national cultures are different from or similar to the culture of the host [23]. A number of researchers have aimed to conceptualise differences in culture. Three of the most noteworthy researchers are Hall [7] who conceptualised differences in culture by referring to high and low-context communication, Hofstede [17] who conceptualised cultural differences by his cultural dimensions model, and Lewis [7] who classified cultures into Linear-active, Multi-active and Reactive groups.

These classifications provide useful dimensions as a means of which to compare and better understand the different cultures relevant to this study; the culture of KSA and that of other countries. These cultural dimension models are helpful for making broad generalisations. The aggregate impact of the analysis of KSA's cultural dimensions is that Western expatriates, such as from the United Kingdom (UK), can experience a cultural shock due to the large CD between the culture of KSA and that of the UK, compared with expatriates from another Arab country such as Jordan, that have a smaller CD. This is in support of other expatriate adjustment theorists such as Black [21], Tung [1] and Haslberger [23]. Expatriates that are part of a compound community are therefore protected from their perceived differentness of KSA culture. The cultural shock usually experienced by expatriates is amplified when the CD is large. Cultural shock refers to disillusionment and increasing frustration with the surroundings as the initial infatuation with the host country wears off and when expatriates realise they have to settle in a new routine (Lysgaard (1995 cited in [20]). Aspects that usually trigger this are the language barrier as well as stark differences in social issues such as: public hygiene, traffic safety, and the type and quality of the food [24]. Johnson et al [25] stated that even the most routine tasks such as buying a newspaper or calling a taxi requires mental preparation or even assistance, for expatriates in general. However, for expatriates in KSA even such routine tasks postulates the added problem with the restrictions placed on it. For example, newspapers are filtered [Interviewee 3] which can give a skewed picture of current events in KSA. Furthermore, visiting friends [Interviewees 8, 22], doing grocery shopping [Interviewee 16] and dropping school kids off at school on a regular day [Interviewee 16], are more challenging because women are not allowed to drive. Also, due to the Internet content filtering, expatriates cannot do something as frivolous as catch up with the latest celebrity gossip on the Internet [Interviewee 20].

Due to the large CD between some expatriates' home cultures and that of the host culture, the compound community protects expatriates from the relatively harsh realities of life in KSA such as the rules and regulations. For example one interviewee noted:

KSA has many legal and cultural limitations for women that make life challenging. Matters such as not being able to drive, needing sponsorship to work and not having freedom of speech (comparatively to Lebanon) are all limitations that I have experienced.

[Interviewee 10]

Even for those expatriates from countries that are not so culturally different from KSA, a CD is still evident. A single Jordanian woman indicated this:

"Living in KSA is not much different from living in Jordan or any other Arab country. It's all based on the way we were brought up. One of the little differences is that in Jordan everything is available and we can freely decide what to do and what not, on the other hand in Saudi Arabia the law limits your options and your freedom to choose".

[Interviewee 11]

Expatriates that find happiness in KSA need therefore to find a balance between the local life in KSA and the life they want to live. This is accomplished by creating a routine that may include a number of compromises. The "expatriate's status", that is, whether the expatriate is accompanied or unaccompanied/single, is influenced by the CD as there are physical restrictions, imposed by the customs and laws of the country, on single or unaccompanied expatriates.

Aside from the obvious restrictions on life outside the compound like wearing trousers and shirts (as opposed to shorts and T-shirts in the heat), prayer time closing [shops] five times a day or having to eat in the singles section of restaurants, there are many other restrictions. I have been denied access to 
supermarkets and shops as a man on my own, making buying a pint of milk very hard if it happens to be on a Friday, which is deemed family time!

[Interviewee 12]

Contact between expatriates and the locals are not common and therefore divide the expatriate from a local "social support network" which they would normally receive from the interaction with the locals. The lack of contact is usually due to the lack of understanding of the cultures, by both parties. From the locals' point of view - they see anyone not from the same faith and culture as inferior, therefore they do not as a rule spontaneously socialise with the expatriates. Conversely, due to a lack of understanding of the local culture and customs, expatriates tend to steer away from building relationships with the locals.

In Saudi the people are not allowed (for the lack of a better word) to interact. They don't agree with our culture and religious views and in some cases are openly aggressive about it.

[Interviewee 1]

I think once you know a little about a culture, make a few local friends, get out and experience local life a little you are less fearful. . .

[Interviewee 13]

The discussions above relate to how CD contributes to the "degree of isolation" experienced by the expatriate. The challenges are usually physical limitations posed on the expatriate to some extent. The extent of the impact of CD does however depend on the expatriate's personal previous experiences, which can reduce the cultural shock.

\section{DEGREE OF ISOLATION}

In [9] it was argued that the "degree of isolation" experienced by expatriates is a multifaceted concept which is an important antecedent of adjustment. The degree of isolation describes the extent to which expatriates experience the feeling of isolation. It is a subjective concept as implied by the word "degree". The extent to which isolation is experienced depends on a number of factors: individual differences, personality traits, previous experience, status i.e. accompanied or unaccompanied, the CD, and the level of support available. "Degree of Isolation" in the context of the current study is important because it contextualises the situations under which the Internet is seen as a lifeline to the real world. It extends the idea that life in KSA is different from "the real world". The following section will define what is considered "real", from the expatriate perspective. This in turn will influence how the Internet is used and perceived by expatriates in this study. Section 7 will reference how and what the impact of "degree of isolation" is on the emotional well-being of the expatriate.

\section{6 'REAL WORLD' VS 'EVERYDAY LIFE'}

This section will introduce and define the concepts of "real world" and "everyday life". The definition of the "real world" is relative to the expatriate and his/her degree of adjustment. The tradeoff between "real world" versus "everyday life" exists because $95 \%$ of the interviewees refer to the fact that they do not consider life "real" or "normal", sometimes describing it as "alien", "a strange existence", "challenging", "oppressive", or "living in a bubble". Everyday life in the KSA context is mostly very different from the life at home as a consequence of the large CD. Expatriates in this study have described "everyday life" as containing elements which they will not find in the "real world" such as: checkpoints as an everyday occurrence, slavery, no women driving, compound living, restricted movement, restriction on visitors; women need to wear an abaya; and prayer time. The "real world" in contrast contains none of the "everyday" and other elements such as: freedom of speech, freedom as a woman, living close to family, freedom of employment for females, and entertainment facilities such as coffee shops and cinemas.

The definition of "everyday life" is subjective. Everyday life in KSA includes "real world" things such as schools, shops, cars, houses etc. However, due to the rules imposed by the KSA government relating to religious beliefs, there are challenges that exist in the utilisation or enjoyment of "real world" things as is illustrated by the next quote.

One actually has to come to terms with what you are "missing out on"... a NORMAL lifestyle, i.e. doing grocery shopping or any shopping for that matter at your own leisure. To be able to drop my kids off at school on regular week days. To not live a life always pressed for time due to a prayer schedule.

[Interviewee 16]

A review of literature has indicated that other communities have distinguished between the "real" and "everyday" world. Students that cannot wait to complete their studies to work in the "real world" [26] or where students use academic knowledge to solve "real world" problems in order to build sustainable competence [27] or to do "real world lawyering" [28]. Also, prisoners with life sentences obtain a view of the "real world" by watching television [29]. Both these scenarios have an "everyday life", which has more rules and restrictions than the prospective "freedom" which will be afforded by the "real world". This resonates with the case of expatriates where "everyday life" contains more restrictions and challenges than the "real world" as explained above. Furthermore, Wellman and Haythornthwaite [30] described the role of the Internet in everyday life, where everyday life and real world were considered to be one and the 
same. They further explained that the Internet is pervasive, describing it as a "real-world Internet" that does not function on its own, but is embedded in the real-life things that people do, where real-life things refer to everyday tasks.

\section{INTERNET IN EVERYDAY LIFE IN THE KINGDOM OF SAUDI ARABIA (KSA)}

This section presents a narrative of how expatriates use the Internet in their everyday lives. This is important because it defines the "everyday" in the context of this study and aids the reader's understanding when distinguishing it as "lifeline to the real' world" (the core category as illustrated in Figure 1). The section commences with a discussion on Internet service provision to compounds based on information obtained from an Internet Service Provider (ISP) to one of the four compounds where the interviewees reside. Following on this is a discussion on how the expatriates in this study use the Internet in their everyday life. The following two subsections will discuss the two main uses of the Internet by expatriates in KSA: Firstly, as an everyday tool and secondly as an indispensable tool. The former relates to the omnipresence of the Internet where expatriate usage will not differ fundamentally from their usage in their home country. The latter discusses the range of emotional responses from expatriates when the Internet is not available.

\subsection{Internet provision to expatriates in compounds}

The expatriates in this study resided in four different compounds. All four of the compounds provided Internet connection. In one of the compounds there were two Internet Service Providers (ISPs); one provided a $10 \mathrm{MB} / \mathrm{sec}$ shared service and the other provided a $2 \mathrm{MB} / \mathrm{sec}$ dedicated service. One of these two ISPs [Interviewee 23] confirmed that the services are provided through a wireless connection. The compounds are surveyed, transmitters are erected throughout the compound and each villa has a receiver for the wireless signal. The ISP confirmed that the majority of expatriates connect one computer to a router to make the whole villa wireless.

The main problem with the Internet connections in KSA is maintaining a reliable connection that fits the expatriates' needs. Interviewee 23 reported that wireless receivers are usually positioned in the windows of villas as the villas are "steel cages" that makes it difficult to receive the signal. Also, the villas have steel mosquito nets in front of the windows, which cause signal loss. He further comments that as an ISP, his major challenge is the support from the ISP company for which he is a vendor, as their services are not guaranteed, especially over weekends or holidays. He reports that in five years of providing services to the residents in the compound, there was only once a three day, complete loss of service due to a third party incident. In his opinion, Internet speed and cost are not a problem which contradicts the experiences of Interviewees 3, 6, 7, 8, and 12 .

It is the perception of Interviewee 17, a British expatriate, that the uses for the Internet in the UK differs greatly from the uses of the Internet in KSA as nearly every shop/group/club/facility in the UK is on the Internet.

You can do all your shopping, be it household, furniture, groceries and fast food via the Internet and even listen to your radio stations, watch ALL your TV channels and even work from your home, over the Internet.

He observes that in the Middle East in general, the Internet is hardly used commercially although it is now possible to watch Arabic TV channels and find some information of certain shops. Most of the Internet traffic is social media and this is on the increase.

\subsection{Internet as an everyday tool}

The Internet as an everyday tool relates to the ubiquitous nature of the Internet in society, referring to the modern alternative as everyday business. Expatriates in this study, not unlike the general population, access the Internet on a daily basis and in the majority of cases more than once a day. This is illustrated with the following quote:

I use the Internet several times daily and consider it essential to modern life. [Modern life is] using present technology to enhance or make life more comfortable.

[Interviewee 2]

Other interviewees have agreed with this statement by describing access to the Internet as "extremely important" [Interviewee 3], "extremely useful" [Interviewee 5], a "necessity in present environment" [Interviewee 5], "something I rely upon no matter where I live" [Interviewee 7], an "invaluable asset" [Interviewee 9], "very important aspect in my life in KSA" [Interviewees 10 and 12], "important" [Interviewee 11] and "vital for communication" [Interviewee 21]. Furthermore, other Interviewees $[2,3,5,7$ and 13] indicated that their usage of the Internet will not differ significantly when they are home mainly because it is a modern tool and they will use it regardless where they find themselves.

It is evident from the study that all the interviewees, with the exception of Interviewee 23, who was not asked the question, used the Internet to communicate with their family and friends via methods such as email and Skype. The authors reported in [21] on the importance of maintaining contact with the benevolent community such as family and friends. Skype and email are cited as being cheaper or quicker than the alternative, more traditional methods of communication such as the telephone or letters. Expatriates in this study, except for Interviewee 17, did not indicate that they use mobile phones or text messages as a means of communication because using the telephone as a means to communicate was cited as very expensive [Interviewees $3,6,7,12,13]$. The majority of interviewees 
highlighted communicating with friends and family as the most important use of the Internet. This study indicate that expatriates communicate with family and friends to

- share the experience

- maintain ties with them

- maintain the feeling of connection to home/not missing out, and

- render support to spouses at home.

Internet-based communication methods provide social continuity and improve the quality of the expatriate experience abroad by providing social stability and reduce isolation through improved communication with their benevolent communities.

The Internet provides a means where we can remain close to family and friends despite not being face to face. We can share information and find out what is going on at home very quickly.

[Interviewee 1]

Apart from the communication activities, Table 1 illustrates the top ranking of activities conducted over the Internet by the interviewees. These illustrate the advancements of the Internet as an everyday tool which allow society to use it for more and more activities. These activities are similar to those of any Internet user anywhere else in the world. However, in general society, as opposed to life in KSA, people generally have a choice. An alternative, as the next quote illustrates, is either unavailable or a logistical nightmare to accomplish in KSA [Interviewees 3, 5 and 17].

I will still use the internet for communication (with people in KSA) but I will be able to buy newspapers, see the news several times a day on TV if I want and be able to go to the shops rather than use their online sites (although, for ease, I will still probably shop via the internet since it means I do not have the faff of driving, parking etc.). However, in the UK, I can at least go and see something before I buy it, if I want.

[Interviewee 3]

Table 1: Top 5 activities of expatriates in the study

\begin{tabular}{|r|l|r|}
\hline Rank & Activity & Proportion \\
\hline 1 & $\begin{array}{l}\text { Communication with family } \\
2\end{array}$ & $\begin{array}{l}\text { and friends } \\
\text { Entertainment (music and }\end{array}$ \\
& $\begin{array}{l}\text { YouTube, Internet radio, TV) } \\
2\end{array}$ & $50 \%$ \\
3 & e-commerce & $50 \%$ \\
4 & Online banking & $45 \%$ \\
5 & Reading online news (home & $36 \%$ \\
5 & and other) & $32 \%$ \\
5 & days & $32 \%$ \\
\hline
\end{tabular}

Therefore, the Internet is a tool in terms of making it a better expatriate experience and is therefore an important aspect among expatriates. The next section will describe the emotional relationship between expatriates and the Internet.

\subsection{Internet as an 'emotionally indispensable' tool}

This section will illustrate the range of emotions expressed by expatriates in this study when considering the possibility of not having access to the Internet in KSA. The majority of expatriates have indicated that they need access to the Internet more while in KSA than in their home country, mainly because they are removed from their benevolent community. However, when asked whether they would remain in KSA if they did not have the Internet their response ranged from: "I would be able to live here without the Internet but it would be more difficult." [Interviewee 8] to "Without the internet, I would be on my way home tonight." [Interviewee 6]. This indicates that some have an emotional relationship with the Internet to the extent that it will influence whether they would consider coming to KSA, and how long they would stay in KSA.

On the few occasions we have been without the Internet, I feel as if someone has cut off one of my limbs (slight exaggeration, but not much!). Having no Internet connection is extremely frustrating and makes me feel cut off from the real world. I phone my mum on Skype every day, so I miss chatting to her (or I spend a small fortune calling her on my mobile) and it means that I cannot surf the net for enjoyment (shopping), news, what is on the TV etc. I would seriously have to consider whether I could live here without the Internet, it is THAT important to me.

[Interviewee 3]

The range of other feelings expressed by expatriates in the event that they have no Internet connection include: "Isolated" [Interviewees 1,3, 6, 9, 13, 15, 16, 18, 19 and 22]; "Homesick" [Interviewees 1, 20]; "Depressed" [Interviewee 1]; "Frustrated" [Interviewees 3, 8, 13, 16 and 20]; "Annoyed" [Interviewee 3]; "Angry" [Interviewee 3]; "Hamstrung" [Interviewee 16]; "Pathetic" [Interviewee 5]; "Paralysed" [Interviewee 16]; and "Cut off" [Interviewees 3, 5 and 22]. How expatriates use the Internet in KSA is important in order to have insight into what affective benefits expatriates derive from using it. The next section will extend this understanding by defining how "information flow" is understood in this study in order to understand the impact on expatriates' affective state of mind. 


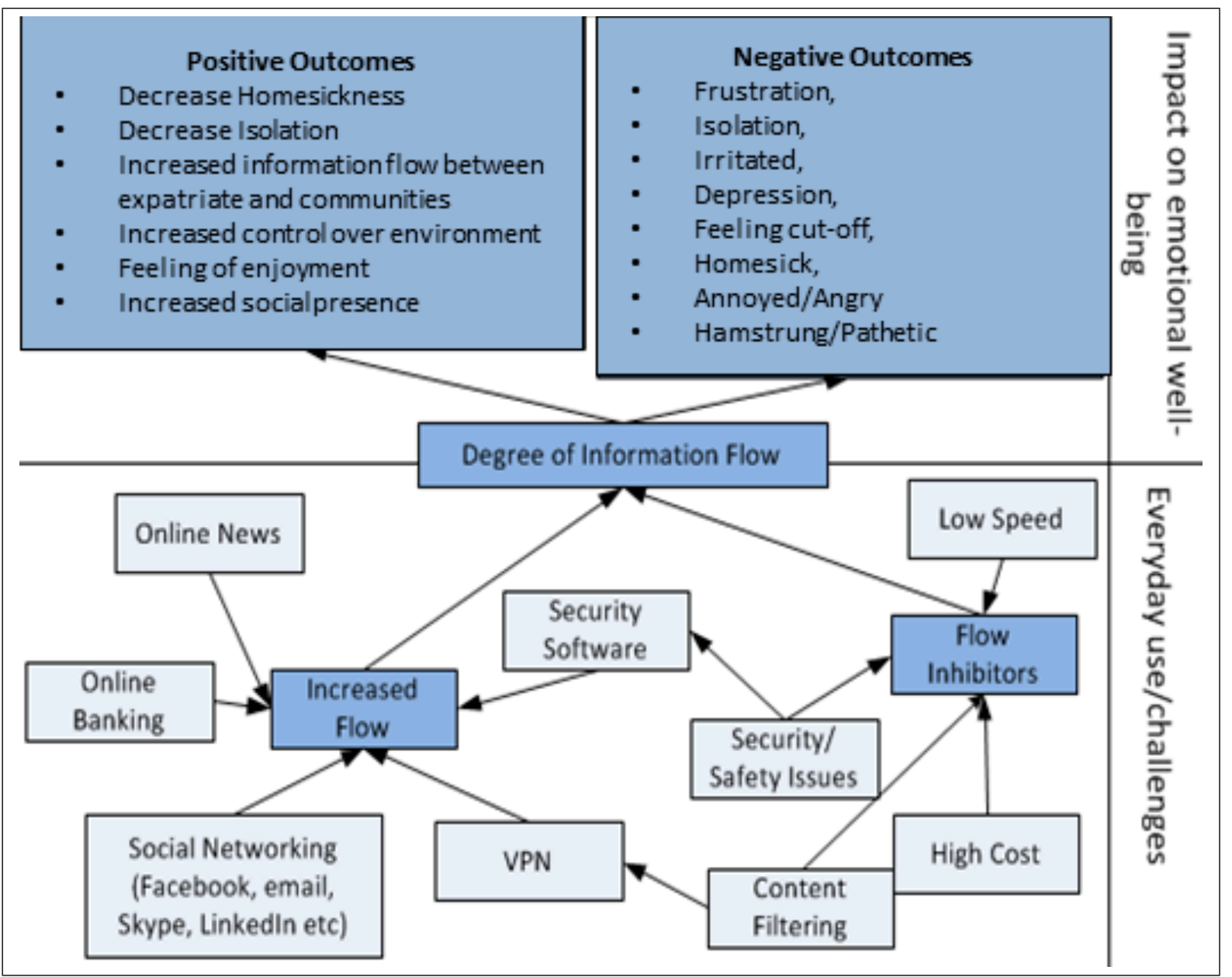

Figure 2: Degree of information flow in this study

\section{DEGREE OF INFORMATION FLOW AS UN- DERSTOOD IN THIS STUDY}

This study has identified a number of factors that would impact the degree of information flow that expatriates experience. Figure 2 illustrates the codes obtained from the interview data generated through the grounded theory methodology as described in Section 2 above. The "degree of information flow" refers to activities on a practical level, the push and pull of information by expatriates. However, as Figure 2 illustrates, the factors that increase and decrease the "degree of information flow" have either a positive effect in the case of the former or a negative effect in the case of the latter on the well-being of the expatriate. This is supported by the work of Hassenzahl [31] who postulates that technologies, such as the Internet play a crucial role in creating and shaping meaningful, positive experiences. However, the outcome of his theory is that the true value of such technologies lies in the resulting experiences:

It is about what we can do and experience with a thing, about the stories unfolding through using a technology, not about its styling, material, or impressive list of features [31].

It is proposed that the role of the Internet in this study transcends the practical level such as the ability to communicate to the emotional level such as the feeling when communicating with family and friends.

Following further analysis, the factors in Figure 2 can be grouped as pre-conditions for information flow, and consequences of information flow, in order to develop the expatriate information flow model as illustrated in Figure 3.

This classification will aid the understanding of the substantive category of "degree of information flow". It will not only account for the factors experienced by expatriates that can cause or inhibit information flow but it also provides an understanding of the positive impact of using the Internet, for example to communicate with family and friends, as a consequence of information flow. The classification of pre-conditions and a consequence of information flow is in line with the notion of the stages of the Flow Theory framework that consists out of three constructs:

1. flow antecedents,

2. flow experience, and

3. flow consequences [32].

In the expatriate information flow model, the consequence of information flow includes the explanation of the experience of information flow. However, it needs to be mentioned that "flow" in the "degree of information flow" as defined in this study is not the same as the "flow" in the Flow Theory developed by Csikszentmihalyi (1975) cited in [33]. Flow Theory 


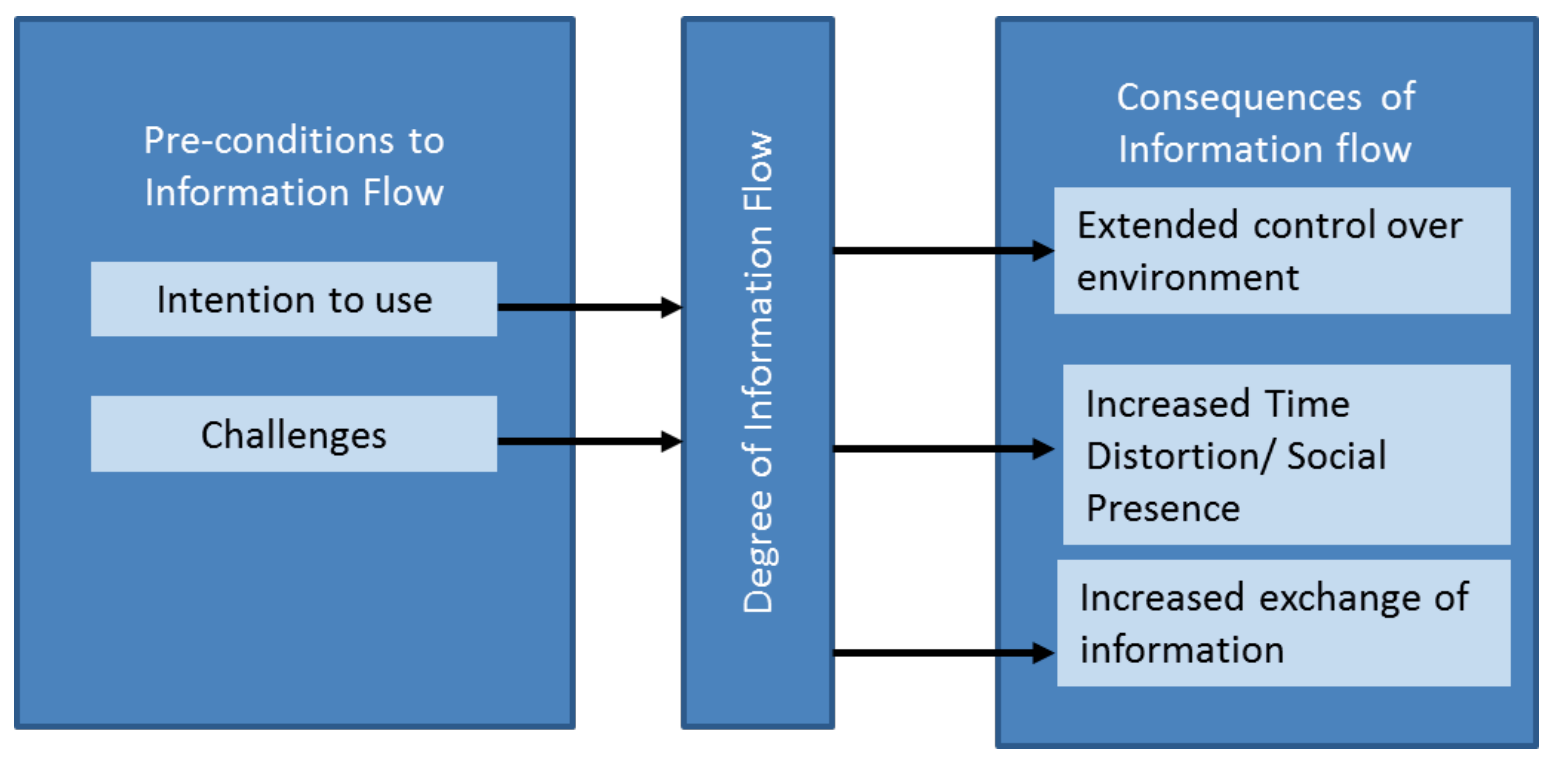

Figure 3: Expatriate information flow model

considers "flow" as the affective state of optimal experience that creates pleasure by balancing the challenge of the task at hand with the skills of the person [33]. "Flow" in this study is therefore operationalised as the affective state expatriates achieve through the flow of information by using their Internet skills as a means to balance the challenges imposed by the culturally different KSA environment.

The Expatriate Information Flow model, as depicted in Figure 3, is briefly described and explained in the following paragraphs.

\subsection{Pre-conditions to information flow}

Expatriates in this study have used the Internet for various means. As reported in Section 6.2, the main activity for expatriates was to communicate with family and friends, with the goal to maintain contact. Immediate feedback was obtained through relatively instantaneous contact, quick and easy. Although the interviewees mentioned other specific uses such as the main activities listed in Table 1 , they also mentioned that they like to "surf" the web to counteract boredom [Interviewees 8, 9, and 16] which is symptomatic of an environment with a lack of social entertainment platforms. The following section will provide an understanding on the challenges expatriates encountered in generating or obtaining effective information flow.

\subsubsection{Challenges with Internet use}

The challenges expatriates encountered when using the Internet, which sometimes led to "frustration", were inflicted by third parties, such as ISPs [Interviewee 3 and 17] and the KSA government rules [34], and was not related to a lack of skill in using the Internet on their part.

This study has identified a number of challenges that expatriates experience which impact on the conditions to obtain information flow (illustrated by Figure 4). Each of these challenges will be discussed next.

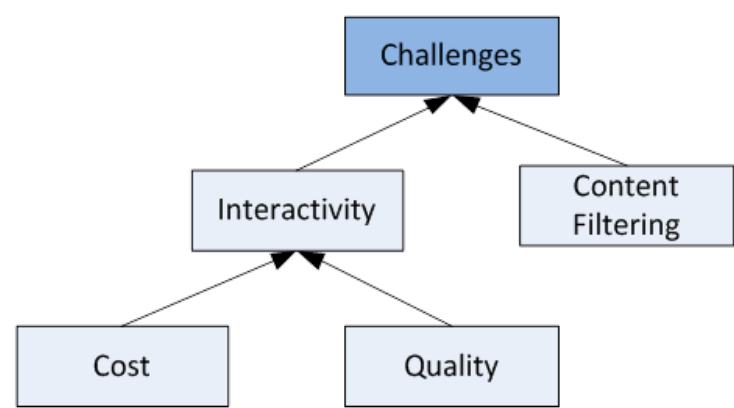

Figure 4: Challenges impacting flow as defined by this study

\section{Quality and cost of internet connection}

The low quality and high cost of Internet connections in KSA is a source of frustration to the expatriates. However, the expatriates report that the frustration associated with the low quality and high cost is endured due to the importance of the Internet in their lives. The following quote illustrates the essence of this:

Internet access has been very difficult due to the poor provision of Internet services. For a long time, we could only access it via a $3 \mathrm{G}$ card and the signal was very poor and intermittent. We have a better link now, although only at $256 \mathrm{~Kb} / \mathrm{s}$, but it is still very expensive. Nevertheless, it is such an important tool to us that we happily pay the price and put up with the frustrations!

[Interviewee 8]

\section{Quality}

Most expatriates are from countries with a high quality of Internet provision (Britain, Canada, America, and Australia) and Interviewee 3 stated that, in her opinion, the Internet provision in the UK is 20 times faster than the service in KSA, and a fraction of the price. Interviewee 7 was concerned about the cost associated 
with subscribing to faster Internet services and whether in fact the ISP offers the speed of service that he desires in order to accomplish a task i.e. download more music and video content. However, the relatively slow services available in KSA have stopped him from doing this. Interactivity is an important factor in humancomputer interaction which would aid a person in generating information flow. Furthermore, high speed will result in "getting immediate response" as a greater speed of interaction contributes to a greater focused attention, social-presence and time distortion [39]. This will be discussed in more detail in Section 8.3.2.

\section{Cost}

Information flow continues despite the high cost as it is indicated that the emotional return on investment which expatriates in this study received from the Internet, outweighs the financial cost associated with gaining access. Interviewee 3 stated that the high price associated with the Internet is "almost irrelevant in terms of what you are getting, i.e. connection to the world outside KSA". This sentiment was supported by Interviewees $[3,6,7,8$, and 12]. Therefore, as illustrated by the quote above, expatriates in this study readily accept the higher prices and persevere with relatively bad Internet connections as connectivity is an important for them. However, even though the relatively high prices of an Internet connection does not inhibit information flow, the low quality of the connection definitely inhibits information flow and increases the physical distance between expatriates and their family and friends. This increase the feeling of isolation and homesickness.

\section{Internet content filtering}

Expatriates in this study are aware of the risks associated with Internet usage just like any other Internet user. These risks are associated with spending too much time on the Internet [Interviewees 1 and 16], revealing too much personal information on the Internet, especially on social networking sites such as Facebook [Interviewees 20 and 22], and the need for appropriate software to protect against malicious programs [Interviewees 4,15 , and 17]. In addition to the strict rules mentioned in Section 1, Internet content is filtered and regulated by the Communications and Information Technology Commission (CITC). Examples of prohibited web pages include pages containing pornographic, illegal, or otherwise objectionable content. This includes pages containing information that are related to drugs, alcohol, gambling, terrorism, bomb-making, and account theft. Copyright infringement is blocked, as well as limited numbers of websites containing extreme cases of slander or abuse directed towards the Islamic religion or Saudi laws and regulations [14]. Content filtering is not just applicable to the Internet in $\mathrm{KSA}$, it is also applied to magazines, printed media, television, etc. which is not part of the scope of this study [34]. Therefore, it is not unsurprising that this study indicates that content filtering of Internet will inhibit flow of information and pose a challenge to expatriates.

You do not get unbiased, unedited news coverage in KSA, you only hear what the government wants you to hear (e.g., strong bias against Israel).

[Interviewee 3]

Expatriates in this study have indicated that content filtering of "innocent websites" leave them "annoyed" [Interviewee 17], "irritated" [Interviewee 18], calling it "ridiculous" [Interviewee 20], "silly as there is always a way around it" [Interviewee 21] and "frustrating" [Interviewee 22].

Content filtering is especially problematic for those expatriates that use Internet for study purposes. Liao [35] has indicated that interactivity was the most important factor for distance learning students, influencing their motivation and behaviour. Interviewee 20 reported that the content filter reduced interactivity by limiting her ability to obtain the necessary information for her studies:

... the filter is ridiculous. My studies are for midwifery based biology course and health sciences. Some of my early course work required me to watch a birthing video but that was blocked. Also when researching the effects of drugs and alcohol on drivers, that information was also restricted.

[Interviewee 20]

Residents, including expatriates can use Virtual Private Network (VPN) to bypass some content filtering issues which would aid information flow. A web search has revealed a number of VPN suppliers who explicitly state on their websites that the system will bypass all content filtering in KSA. However, only Interviewees 12,17 and 18 reported making use of VPN services. Interviewees 17 and 20 stated that they knew which websites to avoid in order not to cast suspicion on themselves as all Internet activities are tracked. Some Interviewees just endure the frustration, such as Interviewees 8 and 22 who attempt to visit "innocent Christian sites". Others, such as Interviewee 19, have not experienced content restrictions yet.

Lawrence Lessig's theory "code is law" is appropriate in the KSA's application of Internet content filtering. It is defined as "[a] rule is defined, not through a statute, but through the code that governs" [36, p. 128]. The theory is based on the premise that technology can fulfil a controlling function or at least have the same effects as the rules do [36]. Figure 5 shows the webpage Internet users get displayed if they try to visit an "offensive" website.

However, it is beyond the scope of this study to comment on the appropriateness of Internet filtering as an effective tool for government to obtain control over online information. With the availability of VPNs, expatriates and potentially the local community can obtain access to "inappropriate" content, and as pointed out by Interviewee 21 , there is always a way to get around the filtering. 


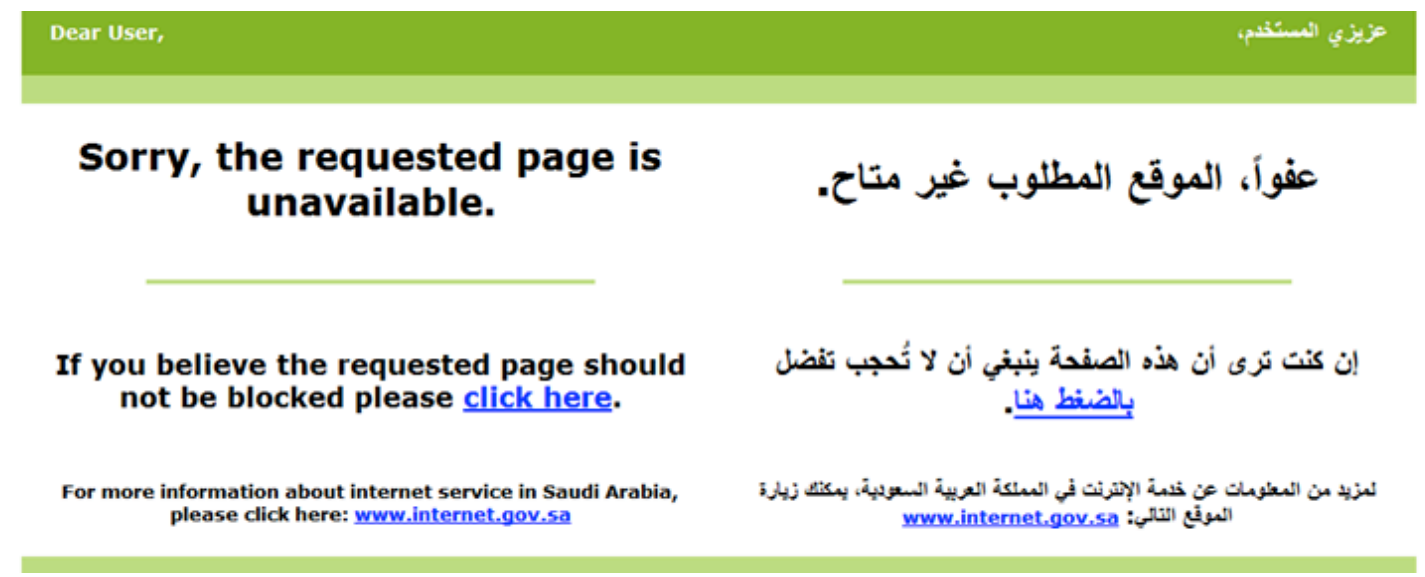

Figure 5: Page displayed when trying to access 'inappropriate' content in KSA

\subsection{Intention to use}

Intention to use refers to Ajzen's theory of planned behaviour [37] which proposes a model which can measure how human actions are guided. It predicts the occurrence of a particular behaviour, provided that behaviour is intentional. Intentions are the precursors of behaviour. In this study, intention to use is defined as the expatriates' intentional use of the Internet. All expatriates in this study have indicated that they use the Internet daily, often more than once a day, with the exception of Interviewee 14.

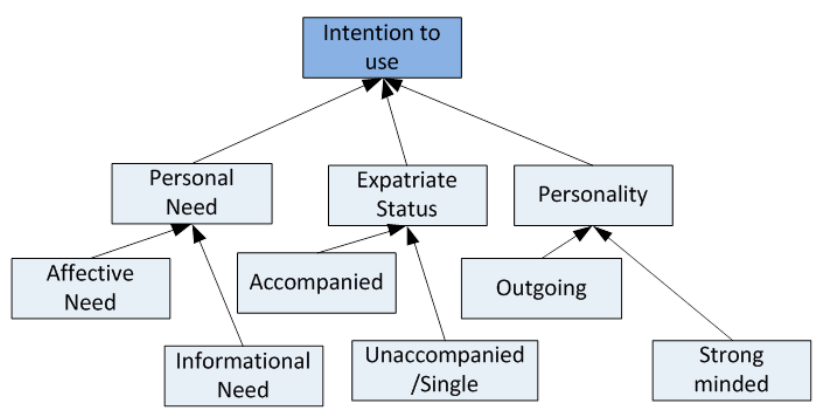

Figure 6: Intention to use as defined by this study

This study has indicated that the intention to use is influenced by an expatriate's personal need, status and personality, as illustrated in Figure 6. These constructs refer to the expatriate as an individual and the use of the Internet as subjective action, although intrinsically motivated due to the dependence on it. Intrinsic motivation refers to engaging in activity without receiving reinforcement other than enjoyment [38]. Each of these constructs will be briefly discussed next.

\section{Personal need}

As discussed in [9]] expatriates in this study have different needs which include:
(a) physical safety
(b) the ability to communicate with family and friends quickly and frequently
(c) quality of education
(d) availability of medical resources
(e) need for entertainment

(f) the ability to buy/obtain home country products

(g) the ability to integrate with local community

In terms of using the Internet, these needs can be classified as either affective needs or informational needs. The former relates to the expatriate's emotional well-being which improves when the expatriate communicates with their family and friends, their benevolent communities. Furthermore, the Internet provides means not to "miss out" on important family events such as seeing grandparents [Interviewee 20] or seeing cousins [Interviewees 13 and 21]. Furthermore, as an example of the extreme affective reliance on the Internet, Interviewee 8 stated that she needs the Internet to keep her "sanity". "Informational need" refers to reading the online news, doing Internet banking and other modern day activities detailed in Table 1. Access to this type of information impacts the "degree of isolation" experienced by expatriates as it reduces the feeling of "isolation" [Interviewees 1, 3, 6, 9, 13, 15, 16, 18, 19 and 22] and feeling "cut-off" [Interviewees 3, 5 and 22 ] from the world outside specifically.

\section{Expatriate status}

Interviewee 1 indicated that on her previous expatriate experience, when she was single, the need to stay in contact was not as great as now, when being married with children. This study has confirmed that the status of the expatriate does have an impact on the intention to use the Internet. The unaccompanied expatriates [Interviewees 6, 7, 9 (initially), 12 and 17] described how difficult it was to live away from their wives and fianc during their expatriate experience and therefore they are dependent on the Internet to continue that relationship. Interviewee 9 indicated he used Skype with a web camera to see his family and it "makes his time easier". Furthermore, unaccompanied/single expatriates rely heavily on the Internet for entertainment due to the unavailability of entertainment facilities and the rules against mingling with unrelated women in public. 


\section{Personality}

The study of Shaffer et al. [3] has provided strong evidence that the assessment of the individual differences of expatriates could be of enormous value to international human resource managers looking to have adaptable, committed, socially and technically competent individuals on international assignments. In [39] it was proposed that expatriates, especially first time expatriates need to be emotionally stable, able to handle stress, outgoing and agreeable, and open and willing to take risks. Interviewee [9] indicated that because he is an "open person" he "rel[ies] on [his] personality to make friends with people from different nationalities and religions". Interviewees 8 indicated that she is content in KSA but not happy as it is an "unusual kind of life for a Western woman with an education and a mind of my own". She stated that the Internet is invaluable and uses it to navigate around the unique restrictions in KSA. Interviewee 15 indicated his positive approach to life helps him to "look beyond the challenges in KSA" and he relies on his family structure and social network for support. Their intention to use is influenced by their personality and the degree to which they have experienced isolation in KSA. Interviewee 9 has an outgoing personality and is therefore less dependent on using the Internet for his personal needs as defined previously. Whereas, Interviewee 8 is strong minded and relies heavily on the Internet in order to keep her sane. Interviewee 15 provides a more balanced opinion by recognising the challenges in KSA but overcomes them with a combination of support from his family (he is an accompanied expatriate), supplemented by the use of the Internet. Therefore, an expatriate's personality determines how self-sufficient they can be with or without the Internet.

\subsection{Consequences of information flow}

Notable studies on users of information systems find evidence that time and space specific factors can predict user behaviour better than individual differences [32]. This has been confirmed in this study as the intention to use has to do with personality influenced by the needs of the expatriate. It further indicated that expatriates derived a Positive Affect (PA) from their Internet usage. PA is described as feelings that reflect a level of pleasurable engagement with the environment, such as happiness, joy, excitement, enthusiasm, and contentment. These can be brief, longer lasting, or more stable trait-like feelings [40]. Lyubomirsky, King and Diener described PA as the "hallmark of well-being' [41]'. Figure 3 illustrates that a PA is derived from the perceived control expatriates have over their environment and the people they communicate with, increase of social presence and an increased exchange of information between expatriates and their benevolent communities. The following sections will describe each of the constructs informing expatriates $\mathrm{PA}$ in more detail.

\section{Extended control over environment}

Extended control can be defined as the level of one's control over the environment and one's own actions [39]. Using the Internet to "take charge of one's life" was earlier on recognized by Dyson, who was considered a futurist in 1997 when she stated:

The Net offers us a chance to take charge of our own lives and to redefine our role as citizens of local communities and of a global society. It also hands us the responsibility to govern ourselves, to think for ourselves, to educate our children, to do business honestly, and to work with fellow citizens to design rules we want to live by. (cited in $[42$, p. 1])

This definition of perceived control and the predicted role of the Internet to obtain control resonate with the expatriates study as this study has shown that expatriates use the Internet to establish/retain control over their lives whilst in KSA. The perceived control, as illustrated by Figure 7, ranges from deciding who to communicate with, surrounding themselves with familiar things by shopping over the Internet and access to or obtaining information that is restricted in KSA by using a VPN.

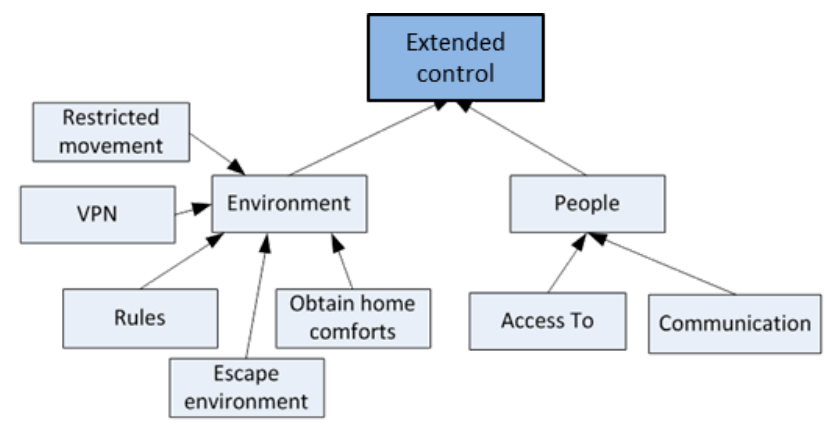

Figure 7: Extended control as defined by this study

There are restrictions on movement especially for women in KSA, as explained in Section 3, as it is illegal for women in KSA to drive. The Internet allows women, including expatriate women, to lead a less sheltered or isolated life. The Internet allows women the ability to let people into their lives. This was the case for Interviewee 11, a single Jordanian woman who lived with her parents, who indicated that the Internet "allows me to control the people I want to have in my life". She further explained that the Internet gives her a "sense of independence" because she has more control to "do what I want when I want without answering to anyone's enquiries about what to do, who to talk to ...etc."

Furthermore, Interviewee 22 indicated that a lot of time is wasted on transport arrangements and that women are dependent on a bus or taxi schedule which makes it difficult to "to come and go". The Internet helps expatriates to make contact with people off compound using e-mail and Facebook. This has been reaffirmed by Interviewee 20 who indicated that she "missed the spontaneity of just being able to pop out" due to the inadmissibility for women to drive in KSA. 
Furthermore, Interviewee 8, referred to shops' prayer times, and the advisability of checking opening times on the Internet (although she concedes it still only gives her a 50-50 chance of being right) a symptom of customer service, which Interviewee 3 argues is very poor.

The expatriates' use of a VPN as a means of bypassing the controls imposed by the KSA government is another example of how expatriates obtain control over their lives in KSA. As reported previously, Interviewees 12,17 and 18 use a VPN to address their main concerns in KSA, which for interviewee 12 was a "lack of places and chances to socialise". Interviewee 17 was reliant on the Internet for entertainment and social interaction.

Interviewees 2, 8, and 9 in this study also indicated that they use the Internet to escape the current environment, which is another means of keeping control over their lives whilst in KSA. Interviewee 2 describes it as "check[ing] what is going on in the free world with the Internet". This also related to the lack of social and recreational opportunities as mentioned previously Interviewee 8 described using the Internet as a means of "killing time, of escaping the harshness of the environment in which I exist". Interviewee 9 uses the Internet to "pass the time" as there are "no cinemas or activities for single people to do".

Expatriates are removed from their own environment and placed in potentially vastly different environments. This is certainly true for expatriates in KSA as the rules and customs in KSA creates a culturally different environment. Interviewees 10 and 22 indicated that living in a compound can simulate life in their own country, referring to freedom of movement and amenities. Expatriates use the Internet to obtain more personal items. Interviewee 15 indicates he uses the Internet to "place first world commodities within reach, at a cost". They surround themselves with things that are important, which for some people might be ordinary things like their favourite recipe off the BBC website [Interviewee 9], receiving religious teaching [Interviewees 8 and 22] and their favourite magazines, greeting cards, clothes [Interviewee 3], and games [Interviewees 5 and 8], downloading music [Interviewees, 2, 5, 8 and 12], and ordering books [Interviewee 13] which are very difficult to obtain in KSA.

\section{Increased time distortion and social presence}

Increased information flow increases time distortion and social presence of expatriates. Both these concepts are in line with the Flow Theory (briefly introduced above), described in [43], [35], [44], [45] and [[46]. Time distortion indicates the degree to which the expatriate loses the sense of time whilst using the Internet [35]. Interviewees have specifically indicated that they lose track of time when "surfing randomly" [Interviewee 3] and using Facebook [Interviewee 20]. Interviewee 3 calls her husband "an Internet widower" as she concedes that she might spend too much time on the Internet. Interviewee 20 also indicated that her husband will tell that she spends "hours each day on
[Facebook]" indicating she is perhaps unaware of how much time she spends on Facebook.

The positive technology framework is concerned with the use of technologies to support and improve the connectedness between individuals, groups, and organisations [31]. It is concerned with obtaining a sense of social presence whilst at a distance. It is a feeling of being socially present with another person at a remote location. Interviewee 17 illustrates this:

Last night I was playing an interactive online game with 3 of my children who are 3500 miles away! I was able to chat with them and give them tasks to keep them busy whilst chatting as if I was really with them.

The study has further shown that the ability to communicate with family and friends is the expatriates' core concern when using the Internet. This is primarily done through Skype and Facebook, which also enhance their social presence. In [47] it was shown that after a user makes a Facebook status update with emotional content, their friends are significantly more likely to make a valence consistent post. The effect of that response was significant even three days later. Kramer $[47$, p. 1] states that

... emotional contagions is possible via text-only communication and that emotions flow through social networks, but also that emotion spreads via indirect communications media.

Conventional computer-mediated communication tools, such as e-mail or text-based chat, are regarded as having lower social presence and social context cues than face-to-face communication. Interviewee 22 stated that making contact through telephone calls and emails helped to negate the feeling of homesickness. When she joined Skype for the first time it was "wonderful" and because she has Skype and Facebook, she has an "instant connection", which has made it easier to be far from home. Interviewee 1 indicated the Internet aids them to "remain close to family despite not being face to face". Interviewee 6 cited various examples of how he uses the Internet to have a continued social presence in his wife's life, for example, helping her to set the thermostat when the power went off, sending her gifts on their anniversary etc. He summarises it as being $100 \%$ dependent on the Internet to stay connected to his family and help them to manage their household while being employed 9000 miles away.

Interviewees 19, 20, and 22 all gave examples where they were able to share important events with their families and helped them to feel that they were not missing out on anything because it's so easy for people to email or Facebook them. This confirms that the heightened information flow experienced by expatriates when using the Internet, especially to communicate with family and friends, generates a PA.

\section{Increased exchange of information}

"Increased exchange of information", as indicated in Figure 8, refers to the way the Internet is instrumental 
in empowering expatriates, making them more aware of other communities and their home country and the world in general. This is important as Sections 3 and 4 explain what expatriates can expect in terms of life in KSA and pointed out key differences in the Saudi culture compared to most Western cultures. In KSA there is no freedom of expression, right to association, open communication through various media/Internet sources, transparency in the areas of justice, political debate or freedom to travel [48].

The Internet has the power to enable a free flow of information and helps create a freer society [36]. In this study it was evident that expatriates are now able to "push" information to their family and friends more quickly, more easily and more frequently [Interviewee 1] than without the Internet. Historically the degree of information flow was very low in KSA due to it being a "closed" society and because of the late introduction of the Internet. Interviewee 14's description of the midnight email club describes the clandestine operation of the Internet in the late 1990s:

The [midnight email] club was a group of young Saudis who wanted to have the Internet before it was available in Saudi. They set up their own network which you call using standard modem and once "online" could chat with others online. They also had a mail system where once every 24 hours they would connect to the real internet-upload and download emails, which was the reason I was using it. It was clandestine in the early days and 'came out' once internet was approved and was one of the first providers here.

Before Internet, expatriates had to wait for a letter to arrive or wait for the weekly phone conversation [Interviewee 3, 13, 18]. However, with the use of the Internet, expatriates are now able to have experiences among a variety of groups, as illustrated in Figure 8.

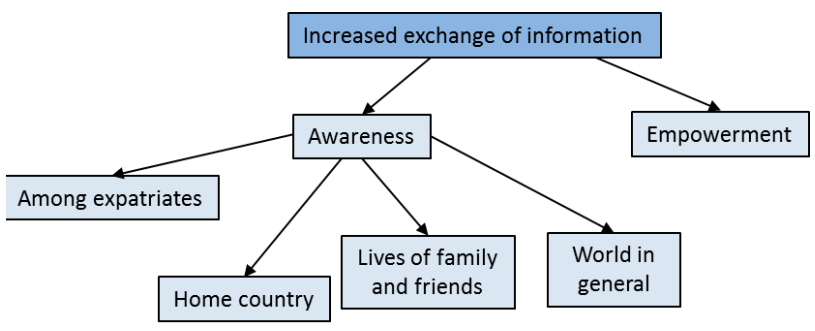

Figure 8: Increase exchange of information as defined through this study

As a result of the Internet the following is enabled:

1. Creating awareness among their family and friends about their lives in KSA very quickly. This is especially important because of the restrictions on visits from family and friends visits are limited to close family members only.

2. Expatriates are more aware of what is happening in the lives of their family and friends, and the rest of the world in general. Interviewee 3 described living in KSA as "living in a bubble" and Interviewee 4 described KSA as a world cocooned within the real world. It is therefore important for them to keep track of what is happening in the world outside KSA.

3. Expatriates are now made more aware of activities within their expatriate community, by receiving email, news from school, etc.

The main method of creating awareness is by using Facebook and Skype. Expatriates use these tools to communicate among themselves and also with family and friends. One of the reasons why this is so successful is because these methods of communication are protected against the strict rules of content filtering as applied in KSA. Social networking sites such as Facebook are nearly impossible to shut down quietly, whereas individual websites and proxy servers are easy for governments to block because they are specific. But if a government were to shut down Facebook, it would alert far too many people of their actions (Woods, 2011 cited in[34]). Expatriates in this study [Interviewees 18, 20 and 22], however, are not convinced that the Internet will help to create awareness between expatriates and the Saudis, mainly due to the rules and regulation grounded in their culture and which are heavily policed. Interviewee 17 feels that although the local community is

physically isolated with their homes surrounded by 10ft walls so they don't even get to see their neighbours, they can also learn of things that they are not allowed to have such as cinemas and theatres.

However, Interviewee 8 feels the Internet can make a change and create an "open society" for the local community and points out that

each step towards freedom for Saudi women does make our lives easier too. The more open the society becomes, the less restrictive it will be for us, and the less suspicion and misjudgement there will be against Western women.

The Internet empowers expatriates by allowing them to take control of their environment as discussed in Section 8.3.1. Furthermore, Interviewee 15 reported that it gives you freedom and he feels restrained without it. For expatriates that are restricted by rules and regulations it is one way of getting away from those restrictions.

It was the opinion of Interviewee 8 that the Internet in KSA plays a role in creating a "more open society" as it gives a "voice" to the local population, especially the women. Upon testing this opinion with other Interviewees, Interviewee 21 indicated that the Internet has succeeded in creating a "virtual open society" that makes life in KSA for expatriate "acceptable". Interviewee 22 indicated that she thinks the Internet has the possibility to create an open society but not in KSA, not due to the "rules and regulations but due to the culture". Interviewee 18 indicated that due to the "rules and regulations" which make the Internet strongly policed, it will not be possible; nevertheless 
it will enable the Saudis to have a greater insight into how people outside KSA live. The latter part was supported by Interviewee 17. Interviewee 19 agreed with Interviewee 22 about the possibility of the Internet to create a more open society but it relies heavily on opportunity to access the Internet freely (referring to the content filtering that was discussed in Section 8.1.1.2) but says it is a generation issue, and it will be the younger generation that will gradually take this forward.

Creating an increased exchange of information between expatriates and the outside world including their benevolent communities, they become empowered and more aware of developments in these communities. This leads to a more pleasant, engaged and meaningful life, which is one of the three pillars of "Authentic Happiness" as defined by Seligman (2001 cited in [45]). This is linked to well-being in the framework of positive technology and therefore, improving the emotional well-being of the expatriates.

\section{CONCLUSION}

This paper reported on an aspect of an on-going study concerning expatriate adjustment in KSA. The primary aim of the research is to contribute towards a better understanding of the role of the Internet in expatriate adjustment in the KSA. Due to the novelty of the situation of expatriates in KSA, the best way to make a significant contribution was by presenting a substantive theory, grounded on issues experienced by expatriates. This approach enabled the first author to take full advantage of the rich source of data offered by being an expatriate in KSA herself. The study has shown that the expatriates' sense of reality of life in KSA is heavily influenced by the culturally restrictive environment from which expatriates were sheltered by living in Westernised compounds. This influenced their actions when using the Internet.

A preliminary theoretical model, as depicted in Figure 1, was proposed where adjustment in the KSA context is mediated by using the Internet as a lifeline to the "real" world by negotiating the "degree of isolation" and the "degree of information flow" experienced by expatriates. Underlying this theoretical model is the contextual concept of culture due to the large cultural difference in the culture of KSA and that of the culture of the expatriates' home countries. This is made apparent through the discussions regarding the customs and rules applied, and what expatriates need to adhere to, whilst in KSA. The impact of the cultural differences is visible in the distinction expatriates made between "real" world and everyday life. The study has shown that this distinction between what expatriates consider as "real" and "everyday" heavily influenced how they used and perceived the Internet. Furthermore, the extent to which they experienced isolation informed by their status, living on a compound, interaction with the local community and their state of mind, also influenced the role the Internet played in their lives.
It is shown that the Internet is an integral part of the lives of expatriates and is more than just a medium that facilitates communication. The paper illustrates that expatriates, not unlike any other Internet user regardless of their location, use the Internet as an everyday tool for communication, entertainment purposes, e-commerce activities, online banking, reading online news, etc. However, the study has indicated that expatriates have an emotional relationship with the Internet, on which they are dependent to decrease the feeling of isolation, decrease feelings of homesickness, increases communication between expatriates and other communities, give expatriates increased control over their environment, create feelings of enjoyment and increase their social presence. Furthermore, without the Internet, or the idea of not having access to the Internet invoked feelings of frustration, isolation, irritation, depression, feeling cut-off, homesickness, annoyance, anger, hamstrung and feeling pathetic.

The role of the Internet was explained by developing an Expatriate Information Flow Model as depicted in Figure 3. This model indicates the constructs that influence information flow (pre-conditions of information flow) include the challenges associated with Internet service provision in KSA that includes the Cost and Quality of Internet connection and Internet content Filtering. These challenges are a direct result of the environment in which expatriates find themselves, as the general opinion of Internet provision in KSA is that it is very slow and expensive but what they get in return is worth the frustration and money. The second pre-condition to information flow was expatriates' intention to use the Internet. This was informed by their status (single/unaccompanied vs accompanied), their personality and their personal needs. The latter is heavily influenced by the expatriate status, as unaccompanied expatriates expressed a greater need for the Internet to stay in contact with their families. The study has shown that the impact of information flow had a positive effect on the well-being of the expatriates as they had extended control over their environment which includes increased access to people, their ability to increase their social presence with benevolent communities and the increase in the exchange of information between themselves and the benevolent communities.

Future papers will report specifically on the mediating role of the Internet between the two substantive categories: "degree of isolation" and "degree of information flow". The discussions will include the impact of these categories on the concept of adjustment, relating it back to literature on expatriate adjustment. That will then present the completed substantive theory on the role of the Internet in expatriate adjustment in $\mathrm{KSA}$.

\section{REFERENCES}

[1] R. L. Tung. "Corporate executives and their families in China: The need for cross-cultural understanding 
in business". Columbia Journal of World Business, vol. 21, no. 1, pp. 21-25, 1986.

[2] M.-F. Waxin and A. Panaccio. "Cross-cultural training to facilitate expatriate adjustment: It works!" Personnel Review, vol. 34, no. 1, pp. 51-67, 2005.

[3] M. A. Shaffer, D. A. Harrison, H. Gregersen, J. S. Black and L. A. Ferzandi. "You can take it with you: Individual differences and expatriate effectiveness." Journal of Applied psychology, vol. 91, no. 1, p. 109, 2006.

[4] Anon. "Global relocation trends 2010 survey report". Online at http://www.articles.totallyexpat.com/globalrelocation-trends-survey-2010, 2010.

[5] H. Richardson. "Postmodern uses of Websites for corporate employees: Helping expatriate families in a political crisis". In Proceedings of 4 th International Critical Management Studies Conference, pp. 04-06. 2005.

[6] H. H. Hiller and T. M. Franz. "New ties, old ties and lost ties: The use of the internet in diaspora". New Media Es Society, vol. 6, no. 6, pp. 731-752, 2004.

[7] J. Barkai. "Cultural dimension interests, the dance of negotiation, and weather forecasting: A perspective on cross-cultural negotiation and dispute resolution". Pepperdine Dispute Resolution Law Journal, vol. 8, no. 3, 2008.

[8] G. Glasze. "Segregation and seclusion: The case of compounds for Western expatriates in Saudi Arabia". GeoJournal, vol. 66, no. 1-2, pp. 83-88, 2006.

[9] M. Hattingh, M. Matthee and H. Lotriet. "Internet use and expatriate adjustment: Understanding the degree of isolation experienced in kingdom of Saudi Arabia". In Proceedings of the South African Institute for Computer Scientists and Information Technologists Conference, pp. 167-177. ACM, 2012.

[10] M. Hattingh, M. Matthee and H. Lotriet. "Towards understanding how expatriates use the Internet in the Kingdom of Saudi Arabia". In Web Society (SWS), 2011 3rd Symposium on, pp. 46-52. IEEE, 2011.

[11] B. G. Glaser and J. Holton. "Remodeling Grounded Theory." In Forum: Qualitative social research, vol. 5. 2004.

[12] B. L. Fredrickson. "The role of positive emotions in positive psychology: The broaden-and-build theory of positive emotions." American psychologist, vol. 56, no. 3 , p. $218,2001$.

[13] B. Dick. "Grounded theory: a thumbnail sketch". Online at http://www. scu. edu. au/schools/gcm/ar/arp/grounded. html (accessed 1.6. 10), 2005.

[14] C. of Commerce and Industry. Riyadh Today 2011. Jeddah, Saudi Arabia: Arab Circle for Advertisement, 2011.

[15] P. Naithani and A. Jha. "Challenges faced by expatriate workers in Gulf Cooperation Council countries". International Journal of Business and Management, vol. 5, no. 1, p. P98, 2010.

[16] J. Ing. Death, isolation, and culture: Testing the validities of terror management theory and coalitional psychology. Ph.D. thesis, Haverford College, Department of Psychology, 2006.
[17] G. Hofstede. "Dimensionalising cultures: The Hofstede model in context". Online at http://scholarworks.gvsu.edu/orpc/vol2/iss1/8/, 2011.

[18] Y. Fan. "A classification of Chinese culture". Cross Cultural Management: An International Journal, vol. 7, no. 2, pp. 3-10, 2000.

[19] L. Romani. "Culture in management: The measurement of differences". International Human Resource Management, p. 141, 2004.

[20] G. Pires, J. Stanton and S. Ostenfeld. "Improving expatriate adjustment and effectiveness in ethnically diverse countries: Marketing insights". Cross Cultural Management: An International Journal, vol. 13, no. 2, pp. 156-170, 2006.

[21] J. S. Black, M. Mendenhall and G. Oddou. "Toward a comprehensive model of international adjustment: An integration of multiple theoretical perspectives". Academy of management review, vol. 16, no. 2, pp. 291-317, 1991.

[22] B. Parker and G. M. McEvoy. "Initial examination of a model of intercultural adjustment". International Journal of Intercultural Relations, vol. 17, no. 3, pp. 355-379, 1993.

[23] A. Haslberger. "Facets and dimensions of crosscultural adaptation: Refining the tools". Personnel Review, vol. 34, no. 1, pp. 85-109, 2005.

[24] G. Mavrides. "Culture shock and clinical depression. Foreign teachers' guide to living and working in China". Online at http://middlekingdomlife.com/guide/cultureshock-china.htm, 2011.

[25] E. C. Johnson, A. L. Kristof-brown, M. R. Klein et al. "Expatriate social ties: Personality antecedents and consequences for adjustment". International Journal of Selection and Assessment, vol. 11, no. 4, pp. 277288, 2003.

[26] J. Farrell. "The Real World". Online at http://natureofcollege.org/essays/essays/the-realworld, 2010.

[27] K. Brundiers, A. Wiek and C. L. Redman. "Realworld learning opportunities in sustainability: From classroom into the real world". International Journal of Sustainability in Higher Education, vol. 11, no. 4, pp. 308-324, 2010.

[28] J. Lande and J. R. Sternlight. "The Potential Contribution of ADR to an Integrated Curriculum: Preparing Law Students for Real World Lawyering". Ohio State Journal on Dispute Resolution, vol. 25, no. 1, pp. 247-298, 2010.

[29] R. Johnson and A. Dobrzanska. "Mature coping among life-sentenced inmates: An exploratory study of adjustment dynamics". Corrections Compendium, vol. 30, no. 6 , pp. 8-9, 2005.

[30] B. Wellman and C. Haythornthwaite. The Internet in everyday life. John Wiley \& Sons, 2008.

[31] M. Hassenzahl. "Experiences before things: A primer for the (yet) unconvinced". In CHI'13 Extended Abstracts on Human Factors in Computing Systems, pp. 2059-2068. ACM, 2013.

[32] C. M. Finneran and P. Zhang. "Flow in computermediated environments: Promises and challenges". Communications of the association for information systems, vol. 15, 2005. 
[33] J. Nakamura and M. Csikszentmihalyi. "The concept of flow". Handbook of positive psychology, pp. 89-105, 2002.

[34] J. Green and N. J. Karolides. Encyclopedia of censorship. Infobase Publishing, 2009.

[35] L. Liao. "A flow theory perspective on learner motivation and behaviour in distance education". Distance Education, vol. 27, no. 1, pp. 45-62, 2006.

[36] J.-A. Lee and C.-U. Liu. "Forbidden City enclosed by the Great Firewall: The law and power of Internet filtering in China". Journal of Law, Science and Technology, vol. 13, no. 1, pp. 125-151, 2012.

[37] I. Ajzen. "The theory of planned behavior". Organizational behavior and human decision processes, vol. 50, no. 2, pp. 179-211, 1991.

[38] F. D. Davis, R. P. Bagozzi and P. R. Warshaw. "Extrinsic and intrinsic motivation to use computers in the workplace". Journal of applied social psychology, vol. 22, no. 14, pp. 1111-1132, 1992.

[39] Z. Zhang. "Feeling the sense of community in social networking usage". Engineering Management, IEEE Transactions on, vol. 57, no. 2, pp. 225-239, 2010.

[40] S. Cohen and S. D. Pressman. "Positive affect and health". Current Directions in Psychological Science, vol. 15, no. 3, pp. 122-125, 2006.

[41] S. Lyubomirsky, L. King and E. Diener. "The benefits of frequent positive affect: Does happiness lead to success?" Psychological bulletin, vol. 131, no. 6, p. 803, 2005.

[42] P. Brey. "Evaluating the social and cultural implications of the internet". ACM SIGCAS Computers and Society, vol. 36, no. 3, pp. 41-48, 2006.

[43] H. Chen, R. T. Wigand and M. Nilan. "Exploring web users' optimal flow experiences". Information Technology \& People, vol. 13, no. 4, pp. 263-281, 2000.

[44] R. Rettie. "An exploration of flow during Internet use". Internet research, vol. 11, no. 2, pp. 103-113, 2001.

[45] G. Riva, R. M. Banos, C. Botella, B. K. Wiederhold and A. Gaggioli. "Positive technology: Using interactive technologies to promote positive functioning". Cyberpsychology, Behavior, and Social Networking, vol. 15, no. 2, pp. 69-77, 2012.

[46] Y. X. Skadberg and J. R. Kimmel. "Visitors' flow experience while browsing a Web site: Its measurement, contributing factors and consequences". Computers in human behavior, vol. 20, no. 3, pp. 403-422, 2004.

[47] A. D. Kramer. "The spread of emotion via facebook". In Proceedings of the SIGCHI Conference on Human Factors in Computing Systems, pp. 767-770. ACM, 2012.

[48] I. Alugaiteeb. "Human rights in Saudi Arabia: Current conditions". Online at http://www.boell.org/downloads/almugaiteeb_HRinSaudiArabia_62010.pdf, 2010. 